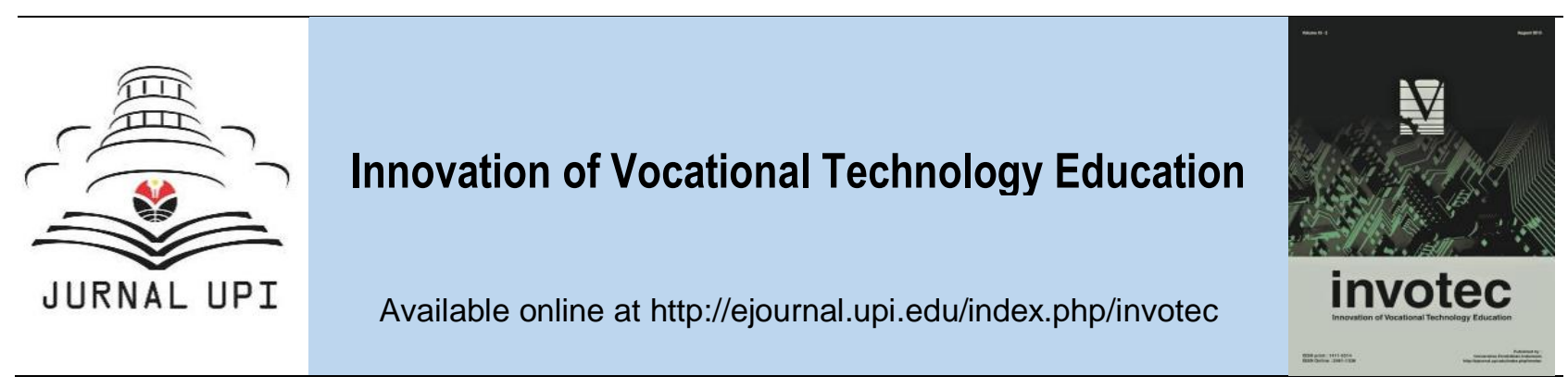

\title{
Developing Alternative Assessment of Mathematical Performance for Vocational Students
}

\author{
Ruslan, Alimuddin, \& Nasrullah \\ Universitas Negeri Makassar, Indonesia
}

\section{ARTICLE INFO}

Article history:

Received 13 November 2017

Received in revised form 15 December 2017

Accepted 29 December 2017

Available online 28 February 2017

Keywords:

Alternative assessment, Mathematical performance, Nurture competencies

Corresponding author: ruslan@unm.ac.id
A B S T R A C T

\begin{abstract}
This research aims to develop alternative assessment that is compatible for mathematical performance and useful to nurture competencies of vocational students. It is developmental research in which there are 3Ds stages such as define, design, and develop. By this, there are three instruments developed, namely Students Performance Test (SPT), Cognitive Affective and Performance Assessment (CAPA), and Holistic and Analytic Assessment (HAA). In order to know the affectivity, not only teachers were getting involved to contribute responds, but also students of SMK Kartika Makassar were engaged to learn and being observed during instruments trial. The result shows that SPT focuses on the ability of identification and drawing, whereas CAPA was divided into some aspects of cognitive (including recall, share exactly, identify symbol and figure accurately, construct the figure), affective (including austerity, motivation, accuracy, and discipline) and psychomotor (including speed, skills, and quality). Lastly, HAA was also constructed in terms of holistic (such as grades, description, and general criteria) and analytic (accuracy of length and angles, compliance figure, and neatness). This study brings the information that alternative assessment can be applied to support classroom assessment in which performance of students should be enhanced, especially for vocational education.
\end{abstract}

\section{Introduction}

Mathematics for vocational students a basic knowledge required to complements their capabilities especially when at work. The improvement of mathematical performance can be reached when workers practice actively in the workplace community (Wedege, 2013; Fitz \& Wedege, 2007; Hoyles, Noss \& Pozzi, 2001; Nunes, et. al. 1993). However, generally teachers in vocational school deliver mathematical knowledge as something surprised or skeptical about the fact that mathematics is a subject of study in their programmed (Wedege, 2013). Jablonka (2003) developed mathematical literacy to be a generic term about mathematical competences in daily life.

The objective of the PISA is to obtain measures of the extent to which students presented with these problems can activate their mathematical knowledge and competencies to solve such problems successfully (OECD, 2004). Wedege argue about three dynamically interrelated 
dimensions which one of them is workers' competences and vocational qualifications. In educational institution, those domains are divided into cognitive, affective, and psychomotor as comprehensive factors built in the students' performance. While vocational qualifications are the knowledge, skills, and personal qualities required to handle technique and work organization in a work function; for example, formal mathematical ideas and techniques (Wedege, 2002, 2004, 2013).

Vocational school or vocational institutions have to show their capacity to provide vocational programs which develop students' performance. This would be reached by the uses of a more comprehensive assessment to the development of performance, rather than one which is essentially prescriptive or behavioristic (Velde \& Cooper, 2000). Constructing assessment, the approach can be applied by concerning the students in terms of the capacity to learn, the capacity to know how to learn, the capacity to know that he has learned (Heron, 1988: 78). To train students with various abilities needs complex approach at the same time (Liao, et. al, 2015); complicated approach should be nurtured with complex assessment.

Along with the curriculum 2013, many vocational schools have devised a series of subjects and assessment tools expressed as needs that must be met. The establishment of mathematical abilities in the workplace supports a foundation of admission of their competences in formal school and vocational mathematics education (Wedege, 2013). By using more comprehensive approaches to improve the higher level competence needs, teachers in vocational college can apply to show their role in the field to reach the benefits of school-based apprenticeships (Velde \& Cooper, 2000).

Combining learning process in the objective of using assessment to assess cognitive, affective, and psychomotor simultaneously in term of performance, alternative assessment is introduced in this article completed assessment indicators. Taking experience from NCLRC (2004), alternative assessment uses activities that reveal what students can do with language, emphasizing their strengths instead of their weaknesses. Alternative assessment instruments are not only designed and structured differently from traditional tests, but are also graded or scored differently. Performance model focus on the required qualifications in mathematics, predefined in terms of skills or competencies (Wedege, 2013).

Developing alternative assessment in this article is an integrated assessment combining mathematical performance and learning domains which are cognitive, affective, and psychomotor. While measuring knowledge, skills and attitude of individuals in an organization to their full capacity (Competence Standards for TVET), realistically, knowledge of students can be identified by the abilities of recall, share, identify, or construct in which being observed through performance test (as focuses on identification and drawing). In psychomotor domain, there are three categories such as speed, skills and quality. Lastly, affective domain is measured by four categories, namely austerity, motivation, accuracy, and discipline (Hall \& Johnson, 1994).

Then, this integrated assessment is used to grade or score differently using alternative assessment rubrics. These rubrics are developed into two kinds such as holistic and analytic. The emphasis in holistic scoring is on what a student does well (NCLRC, 2004). Whereas, analytic assessment focuses on accuracy, compliance, and neatness. In summary, this article share what is alternative assessment of mathematical performance and how to develop it in order to be useful assessment and compatible for vocational students.

\section{Method}

This developmental research was conducted in SMK Kartika Makassar, by using 3Ds steps (Thiagarajan, et.al. 1974), such as define, design, and develop. There are 3 teachers and 28 students who were getting involved to follow this experimental learning, especially for grade XI KR1. The way of developing and constructing assessment we consider four aspects of the affectivity which are validity, reliability, objectivity, and practicality in order to construct Students Performance Test (SPT), Cognitive Affective and Performance Assessment (CAPA), and Holistic and Analytic Assessment (HAA). 


\section{Result and Discussion}

We consider about two things of SPT, which are identification and drawing. As activity to boost those skills, students are given problem of identifying elements of cube based on the characteristics. For example, given a solid figure ABCD.EFGH with all of edges has length $5 \mathrm{~cm}$, what kind of solid figure can be made? Give your explanation and draw the figure! The idea of this problem is not only recall what students know several of solid figure based on the traits, but also trigger students' ability to draw what is in their imagination using information from the problem. What happen next if students are given problem that challenge their imagination and intelligence, this is what we conducted by following the first problem with the question: If the figure in problem 1 we draw a line start from point $A$ to point $C$, so what is the element of this figure can be made? Lastly, to invite how creative students are in drawing mathematical problem. The next context is given 1 perpendicular edge, 3 bottom edges, and 3 surface edges in figure 1 are separated by the completed one, draw the net of remaining figure compatible for given size and naming each of vertices?

CAPA or cognitive, affective, and psychomotor assessment is the assessment combining cognitive domain (including recall, share, identify symbol, and construct), affective domain (including austerity, motivation, accuracy, and discipline), and psychomotor domain (including speed, skills, and quality). While for HAA or holistic and analytic assessment, we consider two things which are holistic (including grades, description, and general criteria), and analytic (including accuracy of length and angles, compliance figure, and neatness). In line with developing stage, we also focus on the affectivity of assessments in terms of valid, reliable, objective, and practice. Therefore, there are four activities in which to exhibit the assessment fulfill the criteria. The first analysis of validity (V) we concern for all of instruments, by using Gregory's (1992) framework to justify the validity of content in the six instruments.

Table 1. The result of content validity using gregory's formula

\begin{tabular}{|c|c|c|c|c|c|}
\hline \multirow{2}{*}{$\begin{array}{c}\text { Type of } \\
\text { Assessment }\end{array}$} & \multicolumn{4}{|c|}{ Frequency of Responds } & \multirow{2}{*}{ V } \\
\hline & A & $B$ & C & $\mathrm{D}$ & \\
\hline SPT & & & & 10 & 1 \\
\hline $\mathrm{CA}$ & & 3 & & 20 & 0,86 \\
\hline AfA & & 2 & & 30 & 0,93 \\
\hline PA & & & & 17 & 1 \\
\hline $\mathrm{HA}$ & & & & 10 & 1 \\
\hline AnA & & 1 & & 15 & 0,93 \\
\hline
\end{tabular}

The information that (Table 1 ) all of $V$ scores are more than $75 \%$. It means that all of kinds of assessment are containing valid content. Especially for SPT, we also examined empirically towards test items of SPT, below is the result after trying out in experimental classroom.

Table 2. The result of empirical validity toward spt

\begin{tabular}{ccccccc}
\hline Types of Performance & \multicolumn{6}{c}{ Coefficient Correlation of Bivariate Pearson } \\
\cline { 2 - 7 } Tests (TPT) & No.1 & Sig. Value & No.2 & Sig. Value & No. 3 & Sig. Value \\
01 & 0,771 & 0,001 & 0,680 & 0,001 & 0,730 & 0,05 \\
02 & 0,841 & & 0,847 & 0,001 & 0,679 & 0,001 \\
03 & 0,881 & 0,001 & 0,708 & 0,001 & & \\
& No. 1a & Sig. Value & No. 1b & Sig. Value & No.2 & Sig. Value \\
04 & 0,806 & 0,001 & 0,486 & 0,009 & 0,757 & 0,001 \\
\hline
\end{tabular}

Table 2 shows that only number $1 \mathrm{~b}$ has coefficient correlation less than 0,5 , while the rests are more than 0,5 . Although number $1 \mathrm{~b}$ is not equal to 0,5 , it is enough to contribute well to the instrument. Therefore, this instrument can be used to measure performance of students empirically. In this test, there are two kinds of reliability test to Performance Test (PT) items, which are internal consistency test and inter-rater reliability. 
Table 3. Measuring reliability of SPT based on internal consistency test

\begin{tabular}{lcc}
\hline PT & Coefficient of Cronbach-Alpha & r-critical value \\
\hline 01 & 0,506 & 0,381 \\
02 & 0,681 & \\
03 & 0,424 & \\
04 & 0,457 & \\
Since r-critical value of the tests is less than that of Coefficient of \\
Cronbach-Alpha, in sig-value of 5\%. Meaning that the items of tests \\
of performance test is reliable being used.
\end{tabular}

The information that (Table 3 ) all of item tests of PT have coefficient of Cronbach's alpha greater than r-critical value. Therefore, the items of PT can be applied reliably. Beside this, there is also inter-rater reliability in which percentage of agreements between experts to justify each of items SPT.

Table 4. Measuring reliability of SPT based on inter-rater reliability

\begin{tabular}{cccccc}
\hline \multirow{2}{*}{ TPT } & I & IT & \multicolumn{2}{c}{ Score of Validator } & Remark \\
\cline { 4 - 6 } & & & I & II & \\
\hline 01 & 1 & 1 & 4 & 4 & $\mathrm{~A}$ \\
& & 2 & 4 & 4 & $\mathrm{~A}$ \\
02 & 2 & 3 & 4 & 4 & $\mathrm{~A}$ \\
& 1 & 1 & 4 & 4 & $\mathrm{~A}$ \\
& & 2 & 4 & 4 & $\mathrm{~A}$ \\
03 & 2 & 3 & 4 & 4 & $\mathrm{~A}$ \\
& 1 & 1 & 4 & 4 & $\mathrm{~A}$ \\
04 & 2 & 2 & 4 & 4 & $\mathrm{~A}$ \\
& 1 & $1 \mathrm{a}$ & 4 & 4 & $\mathrm{~A}$ \\
& 2 & $1 \mathrm{~b}$ & 4 & 4 & $\mathrm{~A}$ \\
& 2 & 2 & 4 & 4 & $\mathrm{~A}$ \\
\hline
\end{tabular}

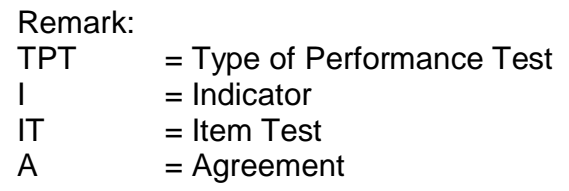

The result of scoring (Table 4) each items of SPT from two experts show that the number of agreement $(A)$ is equal to 11 , then it is 0 for disagreement (D). So can be counted that percentage of agreements: $R=11 / 11 \times 100 \%=100 \%$. In short, the items of SPT can be used reliably in order to assess students' performance in mathematics learning, especially for vocational students. This kind of test was conducted by getting engaged with three observers to assess the objectiveness of each item in the cognitive assessment (CA), psychomotor assessment (PA), affective assessment $(\mathrm{AfA})$, analytic assessment (AA), and holistic assessment (HA).

Table 5. Sig-value of assessment after being analyzed with ANOVA towards observers' responds

\begin{tabular}{ccc}
\hline Assessment & Sig-value & Hypothesis \\
\hline CA & 0,929 & $\mathrm{H}_{0}:$ There is no siginificant difference among items of \\
PA & 0,206 & assessment component assessed by the observers \\
AfA & 0,947 & $\mathrm{H}_{1}:$ There is a siginificant difference among items of \\
AnA & $0,834 \quad$ assessment component assessed by the observers \\
HA & 0,723 & \\
Conclusion & $\begin{array}{l}\text { Since all of sig-values shows that greater than 0,05, meaning that } \\
\text { observers' reponds promoted no siginificant difference among items of } \\
\end{array}$ \\
& assessment component.
\end{tabular}

The information about variance analysis of responds (Table 5) given by observers when they used to apply the assessments in the learning activities. In the column of sig-value, among five 
instruments the minimum score is 0.206 more than that 0.05 (standard of probability value). The result brings the information that there is no significant difference variation of responds to justify the alternative assessment. To assess practicality of the assessment we conducted feasibility test. Table 6 shows that mean of $A_{1}$ is 4 and $A_{2}$ is 3,8 , then the mean score of both assessors is 3,9 . It means that the score is measured in the interval $3<\bar{A} \leq 4$, in category very feasible.

Table 6. Result of assessment's feasibility toward alternative assessment

\begin{tabular}{llcc}
\hline No & \multicolumn{1}{c}{ Indicators } & \multicolumn{2}{c}{ Assessor } \\
\cline { 3 - 4 } & & 1 & 2 \\
\hline 1. & Explain about alternative assessment (Performance and Product) & 4 & 4 \\
2. & Student Performance Test & 4 & 3 \\
3. & Rubric or Scoring Guide & 4 & 4 \\
4. & Steps of Constructing Assessment Rubric & 4 & 4 \\
5. & Determine Score of each Assessment & 4 & 4 \\
& $\quad$ Mean of Score & 4 & 3,8 \\
\hline
\end{tabular}

\section{Conclusion}

The needs of mathematical performance in vocational school or vocational institutions is expected to provide comprehensive competencies rather than essentially prescriptive or behaviorist. In line with providing assessment that is compatible for mathematical performance and useful to nurture competencies of vocational students, alternative assessment is the answer to address one of problems that teachers have. Moreover, to integrate three domains of learning taxonomy and holistic and analytic assessment becomes an integrated alternative assessment is the answer of challenge in order to construct the comprehensive assessment. Providing alternative assessment for vocational students becomes an innovative equipment of teaching and learning is in order to fulfill learners' competencies in the workplace. Alternative assessment of mathematical performance for vocational students in this study consist of Student Performance Test (SPT), Cognitive, Affective, and Psychomotor assessment (CAPA), and Holistic and Analytic Assessment (HAA). After following three Ds steps and having tested in terms of validity, reliability, objectivity, and practicality, the alternative assessment can be applied in learning activities, mainly mathematics lesson.

\section{References}

Fitz, S. G. E. \& Wedege, T. 2007. Developing numeracy in the workplace. Nordic Studies in Mathematics Education, 12(1):49-66.

Gregory, R. J. 1992. Psychological Testing: History, Principles and Applications. Allyn and Bacon: Boston.

Hall, C. \& Johnson, A. 1994. Module a5: planning a test or examination in b. imrie \& c. hall, assessment of student performance. Wellington, New Zealand: University Teaching Development Centre, Victoria University of Wellington.

Heron, 1988. Innovation in assessment: Assessment for learning: guide for new law teachers, http://www.ukcle.ac.uk/resources/assessment/guide/innovations.html, accessed 9/09/16 (the UK centre for Legal Education, The University of Warwick).

Hoyles, C., Noss, R. \& Pozzi, S. 2001. Proportional Reasoning in Nursing Practice. Journal for Research in Mathematics Education, 32(1): 4-27.

Jablonka, E. 2003. Mathematical Literacy. In A. J. Bishop, K. Clements, C. Keitel, J. Kilpatrick, \& F. Leung (Eds.) Second International handbook of Mathematics Education. Dordrecht: Kluwer Academic Publishers. 
Liao, C. W, et. al, 2015. Develop scientific inquiry integrating into project practice teaching of innovative curriculum for vocational high school. International Journal of Information and Education Technology, 5(5).

NCLRC, 2004. Assessing Learning, Alternative Assessment. The National Capital Language Resource Center. Washington, DC. Retrieved from http://www.nclrc.org/essentials/ assessing/alternative.htm.

Nunes, T. A., Schliemann, D. \& Carraher, D. W. 1993. Street Mathematics and School Mathematics. Cambridge, UK: Cambridge University Press.

OECD. (2004). Learning for tomorrow's world. First results from PISA 2003. Paris: OECD.

Thiagarajan, S., Semmel, D. S \& Semmel, M. I. 1974. Instructional Development for Training Teachers of Expectional Children. Minneapolis, Minnesota: Leadership Training Institute/Special Education, University of Minnesota.

Velde, C. \& Cooper, 2000. Students' perspectives of workplace learning and training in vocational education. Education and Training. 42(2):83-92.

Wedege, T. 2013. Workers' mathematical competences as a study object: Implications of general and subjective approaches. Malmō. Faculty of Education and Society. Adults' mathematics: Working Papers, 2. Retrieved from site: http://www.mah.se/ls/eng.

Wedege, T. 2004. Mathematics at work: researching adults' mathematics-containing competences. Nordic Studies in Mathematics Education 9(2):101-122.

Wedege, T. 2002. Numeracy as a basic qualification in semi-skilled jobs. For the learning of Mathematics 22(3):23-28. 